\title{
Multiscale Investigation Of A Less- Damaging Friction Reducer To Mitigate Formation Damage In Unconventional Shale Reservoirs
}

\author{
Rixing Zhang* and Hisham Nasr-El-Din, Texas A\&M University, College Station, USA; \\ Xiaochun Jin, ULTRecovery, Houston, USA; Jun Jim Wu, Phoenix C\&W, Houston, USA; Lisa
}

M. Pérez, Texas A\&M University, College Station, USA

\begin{abstract}
Among the additives in slickwater fracturing, only friction reducers (FRs) are heavy molecular polymers, many of which are polyacrylamide-based. Although they are useful for their intended purpose, FRs rapidly decrease the production rate in shale by damaging the formation. This paper describes the damage mechanism in detail and proposes a less-damaging FR.

Molecular dynamics simulation was used to evaluate how salts potentially encountered during fracturing treatments affect polyacrylamide-based FRs (PAM and HPAM). This work focuses on identifying an ideal less-damaging FR and proposes one based on predictions verified by the experimental results of coreflood simulation tests. Field cases were also conducted, and results show that this less-damaging FR can better mitigate formation damage compared with conventional FRs. Although production decline still occurs in a treated well, it is slower than that of a control well treated with a conventional FR.

The radius of gyration results from molecular dynamics simulations show the salt-tolerant patterns of PAM and HPAM follow a trend in which trivalent ions affect polymers more than bivalent ones, and monovalent ions affect the polymers the least. This result is consistent with results reported in the literature. This research predicts that the polymer chains in a less-damaging FR should be in the medium to shortrange, the polymer concentration should be much lower, and nanoparticle fillers are necessary. The turbidities of the less-damaging FR solutions are almost ten times lower than those of HPAM. In addition, this new FR has only a negligible reaction with selected salts. Coreflood test results indicate that the permeability lost via conventional FR is $92.6 \%$ to $99.8 \%$. In contrast, the permeability damage via the lessdamaging FR is $0.8 \%$. In the field test, two wells on the same platform were treated with two different FRs. After three months of production, a comparative decline of gas production rate in measurable formation damaged by the less-damaging FR (10\% reduction of initiated production rate) and a conventional inverse emulsion FR (30\% reduction of daily gas production) was observed.

This work simulates the trend of conventional FRs affected by salts for the first time. It further provides a systematic method to mitigate formation damage caused by FRs by combining molecular dynamics simulation, prediction, lab tests, and field tests. This procedure is useful for future work as well. A new less-damaging FR has been identified that will prove beneficial for the industry.
\end{abstract}

\section{Introduction}

Oil and gas have been produced economically from shale plays by combining the horizontal drilling and hydraulic fracturing, ushering in a revolution in the shale oil and gas industry. However, the production of oil and gas from shale has declined rapidly over the past few years. For example, in the present study, the

Copyright $(\subseteq$ the author(s). This work is licensed under a Creative Commons Attribution 4.0 International License.

DOI: $10.14800 /$ IOGR.455

Received October 3, 2019; revised November 19, 2019; accepted December 11, 2019

*Corresponding author: zhangrixing1983@gmail.com 
first three months of operation saw a $30 \%$ decline in production, followed by a $70 \%$ reduction over three years. The overall estimated ultimate recovery (EUR) is less than $10 \%$.

It is well known that slickwater is the most commonly used fracturing fluid system. However, this popular method may actually be the cause of the low EUR and rapid production decline. Among the chemicals used in slickwater, only the friction reducer (FR) is a heavy, polyacrylamide-based molecular polymer. All other slickwater components are of such small molecular weight that they cannot be considerable factors in formation damage. Slickwater treatments do perform generally well, barring any external effects, such as encountering metal ions during the treatment procedure. However, in shale formations, there are several metal ions $\left(\mathrm{Ca}^{2+}, \mathrm{Mg}^{2+}\right.$, etc.). During fracturing, pad acid reacts with the metal tubulars, and, as a result, $\mathrm{Fe}^{3+}$ is produced. This iron precipitation proves very damaging to shale formations, and all of the metal ions mentioned here affect FRs. Some biocides also degrade the performance of slickwater fracturing treatments. Researchers have studied formation damage caused by FRs in different ways; however, no systematic multiscale research has to date been conducted. This paper explains the mechanisms of FRs in shale formation damage caused by slickwater fracturing at the molecular scale, pore scale, core scale (permeability change) and reservoir scale (field case). An effective method is found to improve EUR. The present work focuses on samples obtained from the Otter Park and Evie shales.

Formation Damage Causes Oil and Gas Production Rate Decline. As noted in the previous section, FRs are essential to any slickwater fracturing fluid system in shale. However, the chemical components can damage the formation and reduce production (Figure 1). The other elements in Figure 1 includes $\mathrm{Zn}, \mathrm{Ba}$, $\mathrm{Cu}$, and $\mathrm{Mn}$ elements. Si is excluded from the acid digestion results (Peña-Icart et al. 2011; Tessier et al. 1979). Although the majority of the previous research focused on evaluating the friction-reducing performance of these chemicals, only a few studies have addressed the potential formation damage (Ibrahim et al. 2018). Because of the polymeric nature of these chemicals (typically polyacrylamide (PAM)), a FR can cause damage either by creating a barrier on the surface of the formation or by penetrating deeply to plug the pores. In addition, breaking these polymers at temperatures lower than $200^{\circ} \mathrm{F}$ remains challenging (Woodroof and Anderson 1977).

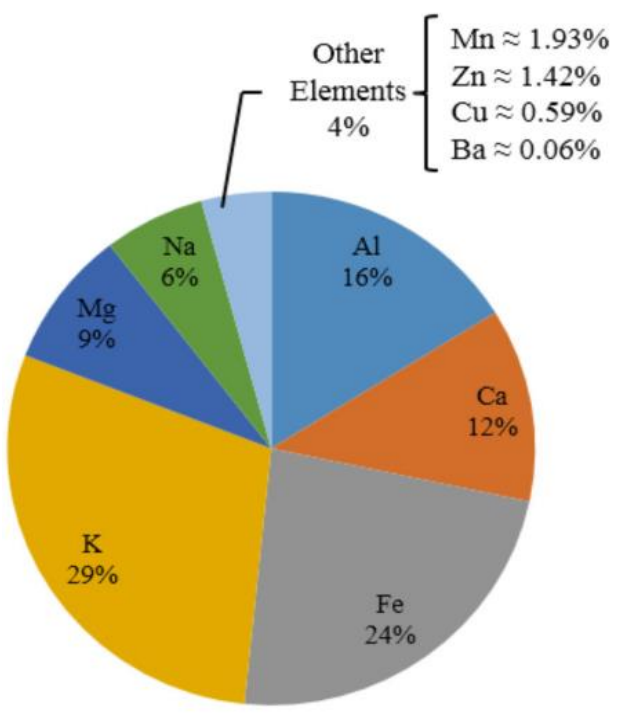

(a)

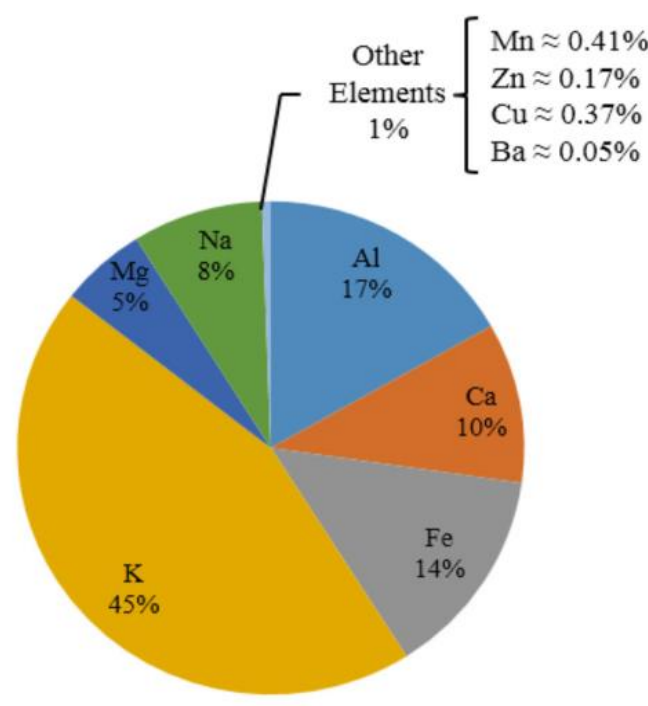

(b)

Figure 1-The six major elements of the (a) Otter Park and (b) Evie shale samples obtained by acid digestion.

The Structure of Shale.The pore-size distribution of shales is mainly small, down to several nanometres. Relatively large pores with poor connections can be up to four microns. Pores can also be connected by thin conduits down to 15 nanometres (Figure 2) (Sisk et al. 2010; Kuila and Prasad 2011). If big polymers are injected to the formation flocculate, the pore throats most likely would be plugged. 


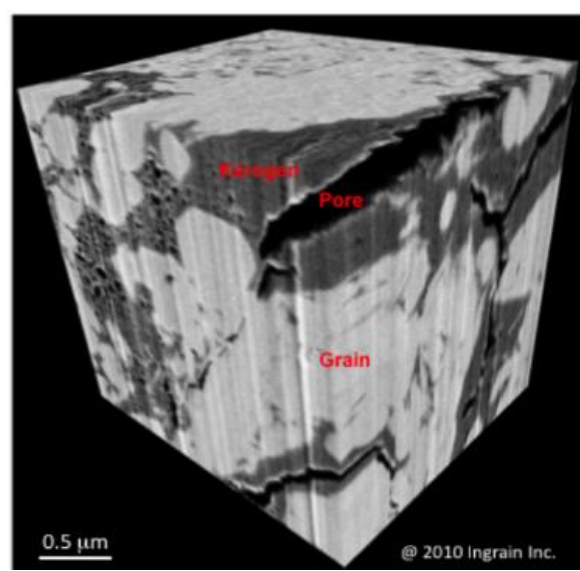

(a)

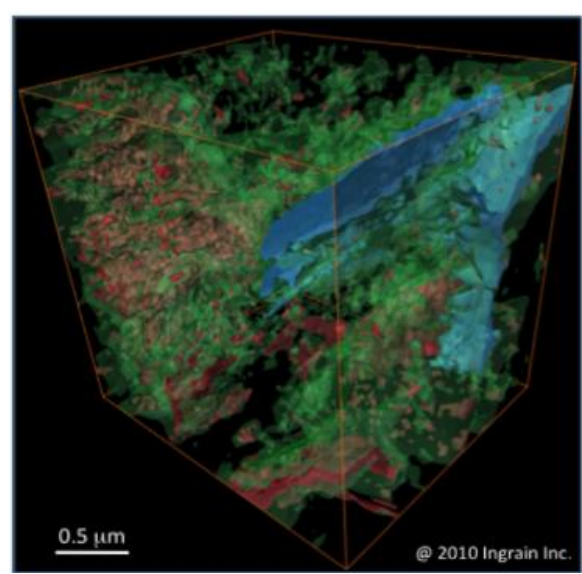

(b)

Figure 2-(a) Rendered volume of shale at the highest nano-resolution. (b) Kerogen (green), disconnected pores (red) and connected porosity (blue). The scale is $\mathbf{5 0 0}$ nanometres.

Fracturing Fluids. Slickwater fracturing was developed and used in other unconventional reservoirs, such as tight gas sand and shale (Carman and Cawiezel 2007). The evolution of fracturing fluids has alternated between oil-based, water-based, and liquefied natural gas fracturing fluids (Barati and Liang 2014). Because the FRs primarily used for slickwater fracturing are polyacrylamides, which are synthetic polymers, the perception was that they would be difficult to break.

The Components of Slickwater. In slickwater fracturing fluid, water, and proppant occupy 99\% of the fluid-system volume (Jackson et al. 2011). Other additives like acid, FRs, surfactant, potassium chloride, scale inhibitor, $\mathrm{pH}$ adjusting agent, iron control agents, corrosion inhibitors, and biocides are also added to fracturing fluid at low concentrations to fulfil different purposes for different fracturing jobs (Figure 3).

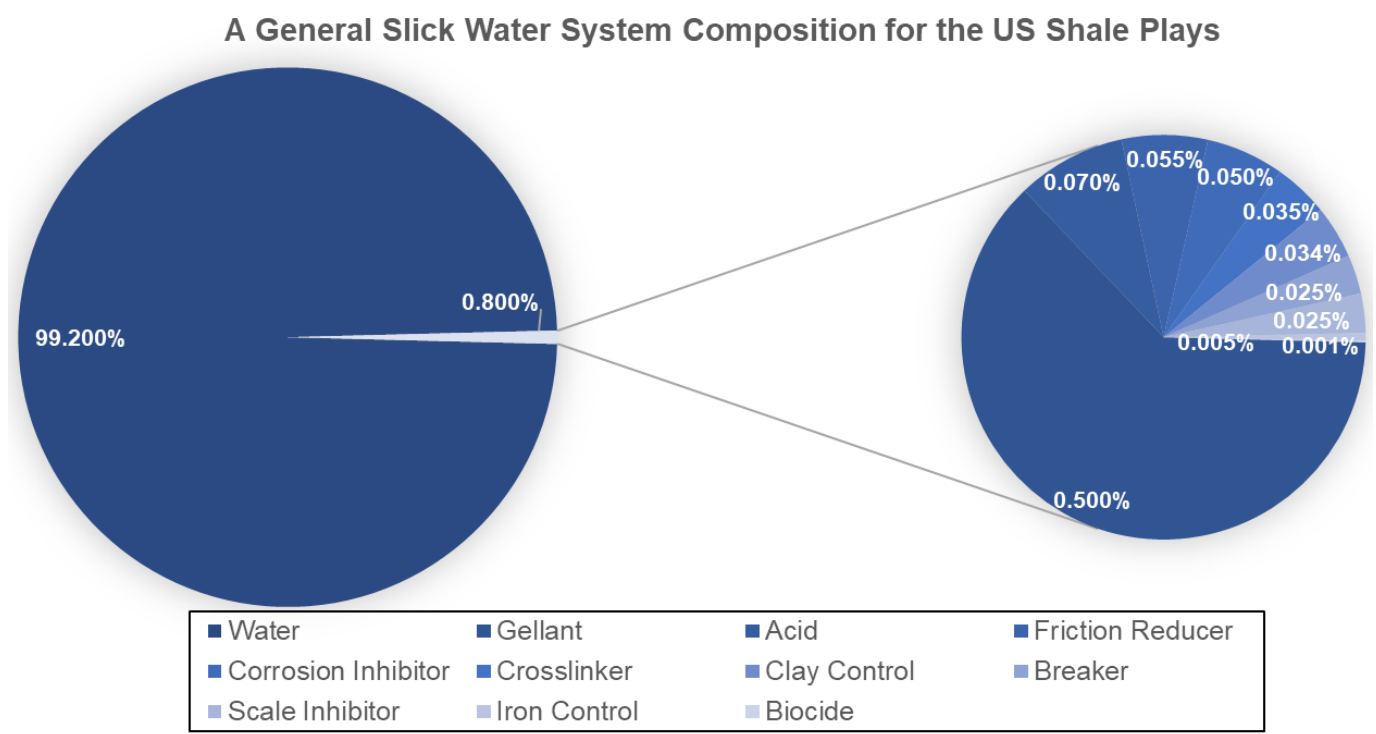

Figure 3-Volumetric composition of a general slickwater system for the US shale plays (edited with source data from www.fracfocus.org).

Metal Ions in Flowback. In flowback, different ions may affect friciton reducers (Montgomery 2013) or other long-chain polymers pumped into reservoirs (Table 1). PAM and HPAM polymers are unstable when temperature increases. PAM-based FR can precipitate in the presence of divalent and trivalent cations, so formation damage could occur (Seright et al. 2009). The cations in flowback water should be considered carefully to prevent the FR from precipatating. 
Table 1-The surface charge density of the focus ions (Essington 2005).

\begin{tabular}{|ccccc|}
\hline Ion & Charge $[\mathrm{C}]$ & Ion Radius $[\mathrm{pm}]$ & Surface Area $\left[\mathrm{m}^{2}\right]$ & Surface Charge Density $\left[\mathrm{C} / \mathrm{m}^{2}\right]$ \\
\hline $\mathrm{Na}^{+}$ & $1.60 \mathrm{E}-19$ & 116 & $1.69 \mathrm{E}-19$ & 0.9462 \\
$\mathrm{~K}^{+}$ & $1.60 \mathrm{E}-19$ & 152 & $2.90 \mathrm{E}-19$ & 0.5511 \\
$\mathrm{Ca}_{2}{ }^{+}$ & $3.20 \mathrm{E}-19$ & 114 & $1.63 \mathrm{E}-19$ & 1.9594 \\
$\mathrm{Ba}_{2}{ }^{+}$ & $3.20 \mathrm{E}-19$ & 149 & $2.79 \mathrm{E}-19$ & 1.147 \\
$\mathrm{Cl}^{-}$ & $-1.60 \mathrm{E}-19$ & 167 & $3.50 \mathrm{E}-19$ & -0.4565 \\
$\mathrm{SO}_{4}{ }^{2-}$ & $-3.20 \mathrm{E}-19$ & 290 & $1.06 \mathrm{E}-19$ & -0.3028 \\
\hline
\end{tabular}

Hydrochloric Acid (HCl) in Pre-Production Can React with Tubing Steel. In US shale fracturing, an acid stage is always used before the slickwater stage. Hydrochloric acid plays a key role in the hydraulic fracturing process. After a natural gas well's hole is bored, drillers will pu mp thousands of gallons of water mixed with acid (typically a $15 \mathrm{wt} \% \mathrm{HCl}$ solution) into the well. The point is to clear out cement debris left over from the drilling stage, and to help open the underground shale fractures. After the acid stage is completed, slickwater and proppant are injected into the well to flush the natural gas out. Although this acid stage serves a useful purpose, the $\mathrm{HCl}$ can corrode the tubulars used for pumping. HCL not only corrodes the tubing steel, but also releases ferrous and ferric ions. The PAM-based FRs participate when encountering ferric ions.

Carbon Steel Composition Summary. During the fracturing treatment, the fracturing fluid must pass through many different tubulars made of several kinds of steel (Table 2). The materials selected are representative of alloys used as tubular goods or downhole equipment.

Table 2-The representative material of tubulars that fracturing fluids pass through.

\begin{tabular}{|c|c|c|c|c|c|c|c|}
\hline Generic Name & $\mathrm{C}$ & $\mathrm{Mn}$ & $S$ & $\mathrm{Ni}$ & $\mathrm{Cr}$ & Mo & Others \\
\hline $4130^{(\mathrm{A})}$ & 0.31 & 0.46 & 0.018 & 0.03 & 0.88 & 0.20 & -- \\
\hline $9 \mathrm{CR}^{(\mathrm{A})}$ & 0.13 & 0.48 & 0.010 & 0.057 & 8.27 & 0.96 & $\begin{array}{l}\text { CU-0.11 } \\
\text { CU-0.10 }\end{array}$ \\
\hline $420^{(\mathrm{A})}$ & 0.38 & 0.36 & 0.010 & 0.37 & 12.70 & 0.05 & $\mathrm{~N}-0.23$ \\
\hline $2205^{(\mathrm{A})}$ & 0.02 & 1.83 & 0.003 & 5.82 & 22.33 & 2.77 & $\begin{array}{l}\text { Co+1- } 19.25 \\
\text { Ti-0.95 }\end{array}$ \\
\hline $718^{(\mathrm{A})}$ & 0.04 & 0.13 & 0.0002 & 53.20 & 18.18 & 3.12 & $\begin{array}{l}\text { Al-3.4 } \\
\text { V-8.2 }\end{array}$ \\
\hline $\mathrm{BC}-\mathrm{Ti}^{(\mathrm{B})}$ & 0.02 & -- & -- & -- & 5.90 & 4.10 & $\mathrm{Zr}-3.1$ \\
\hline $\begin{array}{l}\text { (A) Balance Fe } \\
\text { (B)Balance Ti }\end{array}$ & & & & & & & \\
\hline
\end{tabular}

$\mathrm{FeCl}_{3}$ Always Forms After Acid Flush. In fracturing treatments, among other chemicals, hydrochloric acid is largely used to dissolve minerals and initiate cracks in a formation. During the operation, the acid readily dissolves rust in the tubing or casing and corrodes steel equipments where it is mixed and pumped through. The acid also attacks iron-containing minerals in a formation under treatment. Iron could also be presented in dissolved or suspended form in produced water. When the fracturing fluid mixes with subsurface water and reacts with carbonate rocks and shale, the $\mathrm{pH}$ increases as the acid/fracturing fluid is consumed, and the dissolved iron starts to precipitate in the form of gelatinous iron hydroxide unless an effective iron control system is applied. The insoluble iron precipitation may accumulate in the reservoir and near the wellbore, thereby plugging or reducing the created and natural permeability of the reservoir. Dill and Smolarchuk (1988) have indicated that the above phenomenon, i.e. precipitation of iron in natural and newly developed fractures, is one of the main causes of formation damage. The iron can also precipitate and form scale within the tubing, which also reduces production. 
The dissolved trivalent ferric ions react with polyacrylamide and flocculate in water (Kaşgöz et al. 2003). Water treatments always use this mechanism to remove tervalent ferric ions from water. But this reaction will damage the formation and decrease the friction-reduction rate during slickwater fracturing.

Typical Treatment Procedure of Slickwater Fracking. Several metal ions are generated and dissolved in fracturing fluid and flowback fluid. In the whole procedure, the FR is in a kind of brine environment. Polyacrylamide-based FRs will precipitate when they meet with different salts in water. The sizes of PAM/HPAM polymers are larger than most formation pores but smaller than fracture size. Without metal ions, the formation damage caused by FRs may not be that severe. Reacting with metal ions, however, the PAM/HPAM FRs coil or precipitate, the sizes are much bigger, and the formation damage becomes more serious.

This paper further discusses UV-VIS transmittance tests that indicate how metal ions in water affect HPAM FRs. A new less-damaging FR has much better results in the comparison tests. To summarize, the typical slickwater-fracturing treatment includes the following steps (Table 3).

Table 3-Different stages of slickwater fracturing (Holloway and Rudd 2015).

\begin{tabular}{|c|l|l|l|}
\hline NO. & $\begin{array}{l}\text { Pumping } \\
\text { Steps of } \\
\text { Slickwater } \\
\text { Fracturing }\end{array}$ & \multicolumn{1}{|c|}{ Fluid Injected in Each Stage } & \multicolumn{1}{|c|}{ Function } \\
\hline 1 & An acid stage & $\begin{array}{l}\text { Several thousand gallons of water } \\
\text { mixed with a dilute acid such as } \\
\text { hydrochloric or muriatic acid }\end{array}$ & $\begin{array}{l}\text { This serves to clear cement debris in the wellbore } \\
\text { and provide an open conduit for other frac fluids } \\
\text { by dissolving carbonate minerals and opening } \\
\text { fractures near the wellbore. }\end{array}$ \\
\hline 2 & A pad stage & $\begin{array}{l}\text { Approximately 100,000 gallons of } \\
\text { slickwater without proppant } \\
\text { material }\end{array}$ & $\begin{array}{l}\text { The slickwater pad stage fills the wellbore with } \\
\text { the slickwater solution (described below), opens } \\
\text { the formation and helps to facilitate the flow and } \\
\text { placement of proppant material. }\end{array}$ \\
\hline 3 & $\begin{array}{l}\text { A prop } \\
\text { sequence } \\
\text { stage }\end{array}$ & $\begin{array}{l}\text { May consist of several substages of } \\
\text { water combined with proppant } \\
\text { material (consisting of a fine mesh } \\
\text { sand or ceramic material, intended } \\
\text { to keep open, or "prop" the fractures } \\
\text { created and/or enhanced during the } \\
\text { fracturing operation after the } \\
\text { pressure is reduced) }\end{array}$ & $\begin{array}{l}\text { This stage may collectively use several hundred } \\
\text { thousand gallons of water. Proppant material may } \\
\text { vary from a finer particle size to a coarser particle } \\
\text { size throughout this sequence. }\end{array}$ \\
\hline 4 & $\begin{array}{l}\text { A flushing } \\
\text { stage }\end{array}$ & $\begin{array}{l}\text { A volume of fresh water sufficient } \\
\text { Alume }\end{array}$ & Flush the excess proppant from the wellbore \\
\hline
\end{tabular}

\section{Experimental Studies}

Molecular Dynamics Simulations for PAM and HPAM FRs in Different Salt Water. Molecular dynamics (MD) simulation helps determine the structures and interactions of molecular components in certain force-filled solutions. MD is also a complement to conventional experimental approaches and enables observation of the different processes microscopically. MD serves as a link between microscopic and macroscopic scales of time and length, predicts the bulk properties by simulating molecular interactions and behaviors, and provides a link between theoretical hypothesis and experimental results in this paper. The mechanism of formation damage caused by polyacrylamide-based FRs is also further explained in a later section.

FR Selection. PAM (Polyacrylamide) and HPAM (Partially Hydrolyzed Polyacrylamide) are commonly used FRs. The concentration of PAM and HPAM in slickwater typically ranges from 0.25 to 2 gal/1000 gal. Considering the less FR concentration, the longer the simulation takes, it is better to use relative higher FR concentration during simulations to accelerate this simulation procedure. And FR-related formation damage always happens in reservoirs or after flowback, when much water molecues already filtrate into 
rocks. In that condition, the real FR concentration is high. So, finally, the FR concentration in molecular dynamics simulations was $1.5 \mathrm{wt} \%$, relative higher than normal dose in real treatment on site.

Main Simulation Steps. The main simulation steps included amorphous cells installation, forcite geometry optimization, NPT (NPT means the condition of constant particle number N, constant pressure P, and constant temperature T), NVT (NVT means the condition of constant particle number N, constant volume $\mathrm{V}$, and constant temperature $\mathrm{T}$ ), forcite analysis, and comparison of results and variables optimization.

Parameters for Characterizing Polymer Solutions. The radius of gyration $\left(\mathrm{R}_{\mathrm{g}}\right)$ is used to quantify the conformation alteration of polymer chains. For the same polymer chain in salt water, the smaller the $R_{g}$, the more the polymer chain coils. Then, the coiled PAM/HPAM chains affected by metal ions lost the friction-reduction function and tend to flocculate. The radius of gyration, $R_{g}$, is defined as the root mean square distance of the atoms in the molecule from their common center of mass, that is (Eq. 1),

$$
R_{g}=\sqrt{\left(\sum_{i=1}^{N} m_{i} s_{i}^{2}\right) /\left(\sum_{i=1}^{N} m_{i}\right)}
$$

where $\mathrm{m}_{\mathrm{i}}$ is the mass of atom $\mathrm{i}, \mathrm{s}_{\mathrm{i}}$ is the position of atom $\mathrm{i}$ with respect to the center of mass of the molecule, and $\mathrm{N}$ is the total number of atoms.

PAM Polymer in Salt Solutions. Material Studio 2017R2 software was used to simulate molecular dynamics of PAM-based FRs in different salt solutions. For PAM amorphous cells, one 20-repeat units PAM, $5200 \mathrm{H}_{2} \mathrm{O}$ molecules and different number of metal ions $\left(\mathrm{Ca}^{2+}, \mathrm{Mg}^{2+}, \mathrm{Fe}^{2+}\right.$ or $\left.\mathrm{Fe}^{3+}\right)$ with corresponding number of chlorine ion, $\mathrm{Cl}^{-}$constituted a $53.8 \times 53.8 \times 53.8 \AA\left(1\right.$ angstrom $(\AA)=1 \times 10^{-10}$ meters $(\mathrm{m})=0.1$ nanometer $(\mathrm{nm}))$ cube. Smart algorithm, COMPASS force field, 298K temperature, and 20 ps simulation time were chosen. As a synthetic FR, PAM is a long-chain polymer composed of repeating units of acrylamide (AM) (Figure 4).

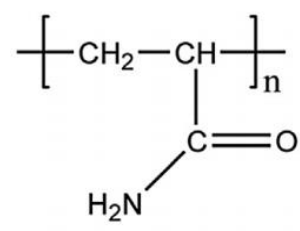

Polyacrylamide (PAM)

Figure 4-Molecular structures of polyacrylamide (PAM).

In this study, 20 repeated units were chosen for molecular dynamics simulations. 3D structure of PAM in this simulation is shown as follows (Figures 5 and 6).

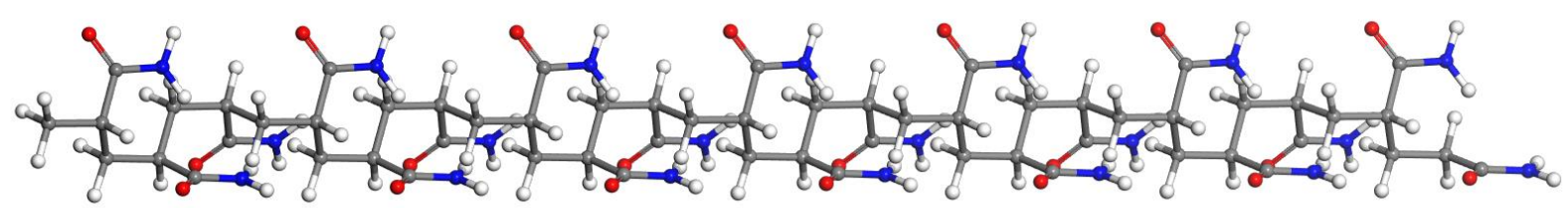

Figure 5-Non-ionic PAM with 20 repeated units.

In Figure 5, the red dots are oxygen atoms, the blue dots are nitrogen atoms, the grey ones are carbon atoms, and the white ones are hydrogen atoms. The whole molecule is composed by 20 -repeat units of PAM polymer. 

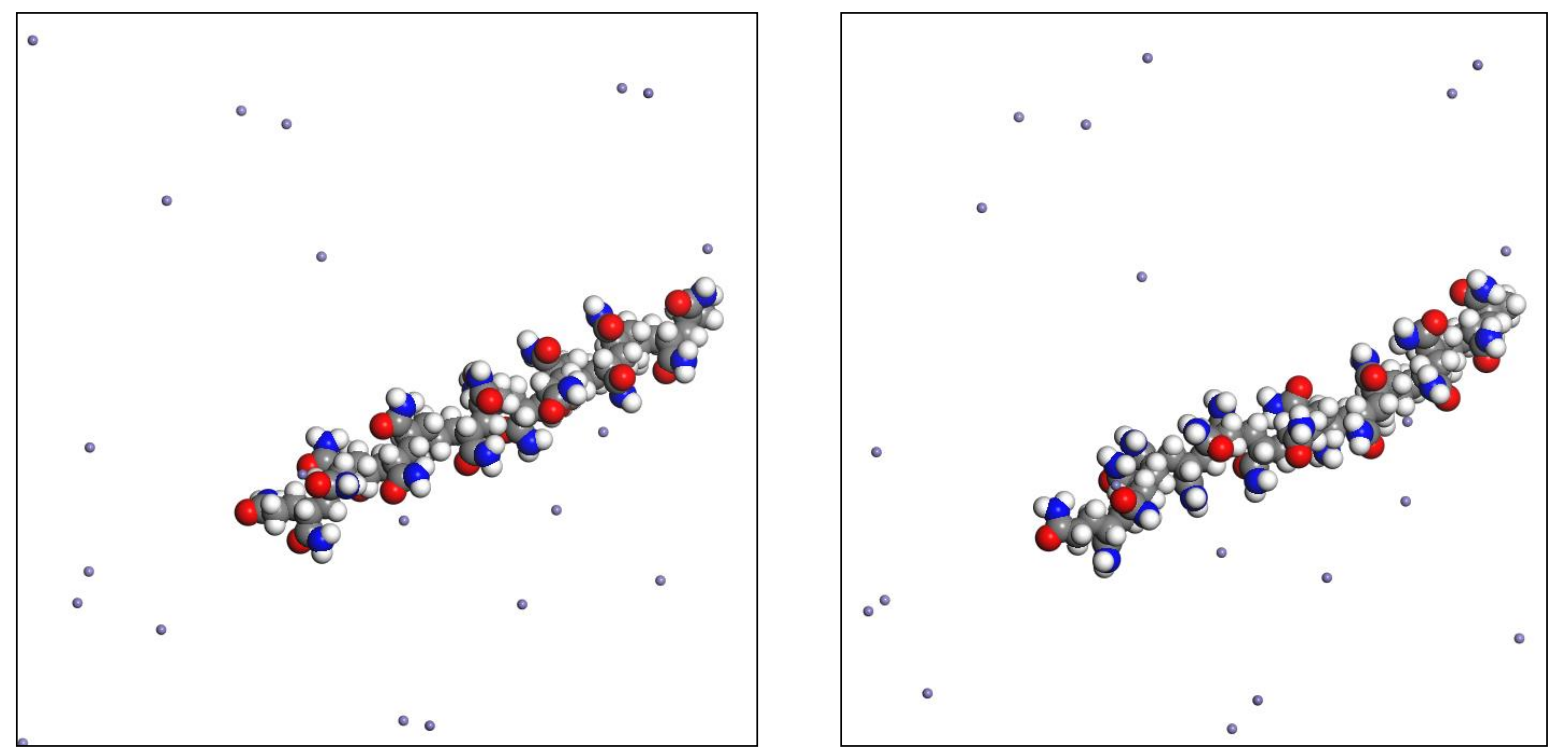

Figure 6-PAM polymer's 3D configuration alteration before NVT beginning (left) and after 20ps simulation (right). Purple dots around the 20-unit PAM molecule are $\mathrm{Fe}^{2+}$.

Take the $\mathrm{FeCl}_{2}$ solution simulation as an example. From the 3D configuration of the PAM molecule changing along with simulation time, it is obviously that the PAM polymer coiled in different metal ions' solutions (Figure 7).

The radius of gyration evolution for non-ionic PAM was analysed. The result shows that PAM coils in all studied solutions. And the calcium ions affects PAM-based solutions less than magnesium, but more than ferrous iron.

The PAM polymers coils in all solution candidates. As the concentration of salt goes up, the radius of gyration for PAM becomes smaller. This result means that PAM coils more. This trend matches hydraulic fracturing treatment industrial field experience. PAM FRs, interacting with ferric ions, lose more frictionreduction rate than when interacting with calcium ions. Therefore, ferrous ions affect PAM FRs less than ferric ions and calcium ions.

\section{Concentration of Salt vs. Radius of Gyration for Polyacrylamide Polymer in Salt Solution (15GPT, $\left.2^{\circ} \mathrm{C}\right)$}

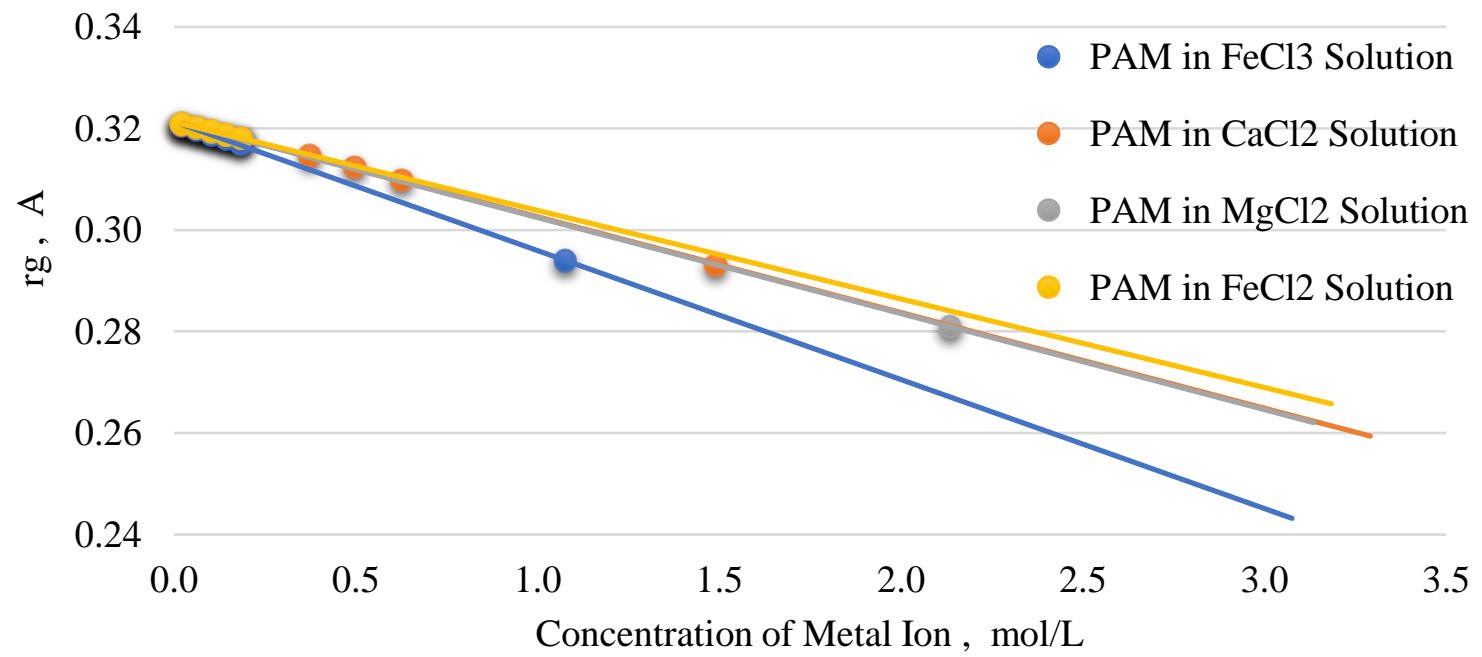

Figure 7-Radius of gyration evolution as PAM interacts with various metal ions in different concentration. 
HPAM in Salt Solutions. HPAM (Partially Hydrolyzed Polyacylamide) is the most common FR available. It is made by reacting sodium acrylate with acrylamide so that approximately $30 \%$ of the acrylamide groups are in the hydrolyzed form (Figure 8). This hydrolyzed form improves the solubility in water, and makes the polymer more compatible with cationic minerals, and is commonly marketed as a $50 \%$ active dispersion in mineral oil. Because it is widely used as a flocculant for water in paper manufacture and the cheapest FR, it is the most widely used in the fracturing treatment(Montgomery 2013).

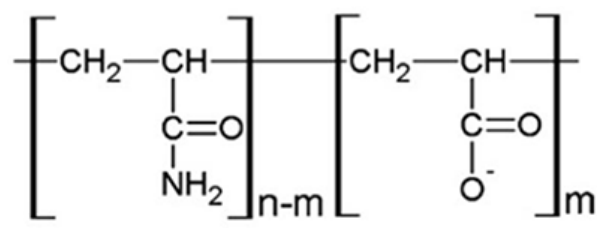

Figure 8-Repeating monomer units of HPAM.

In this study, the structure of HPAM (Yegin et al. 2017) appears below (Figure 9). The value of $\mathrm{n}$ is 5 and that of $\mathrm{m}$ is 2. As shown in Figure 10, by converting concentration unit from weigh percentage to $\mathrm{mol} / \mathrm{L}$, it clearly shows that all radius of gyrations trend lines with monovalent metal ions are overlapped. The trend lines of bivalent metal ions are together in the plot. The trivalent ions' line is far beneath the ones of bivalent metal ions. With the same mole of metal ions, the higher the electrovalence, the more severely the metal ion affect the HPAM polymers.

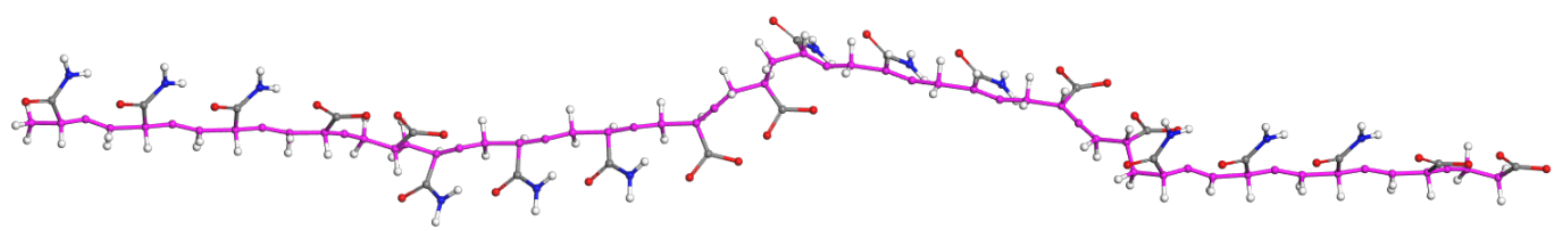

Figure 9-HPAM polymer with 4-repeat units.

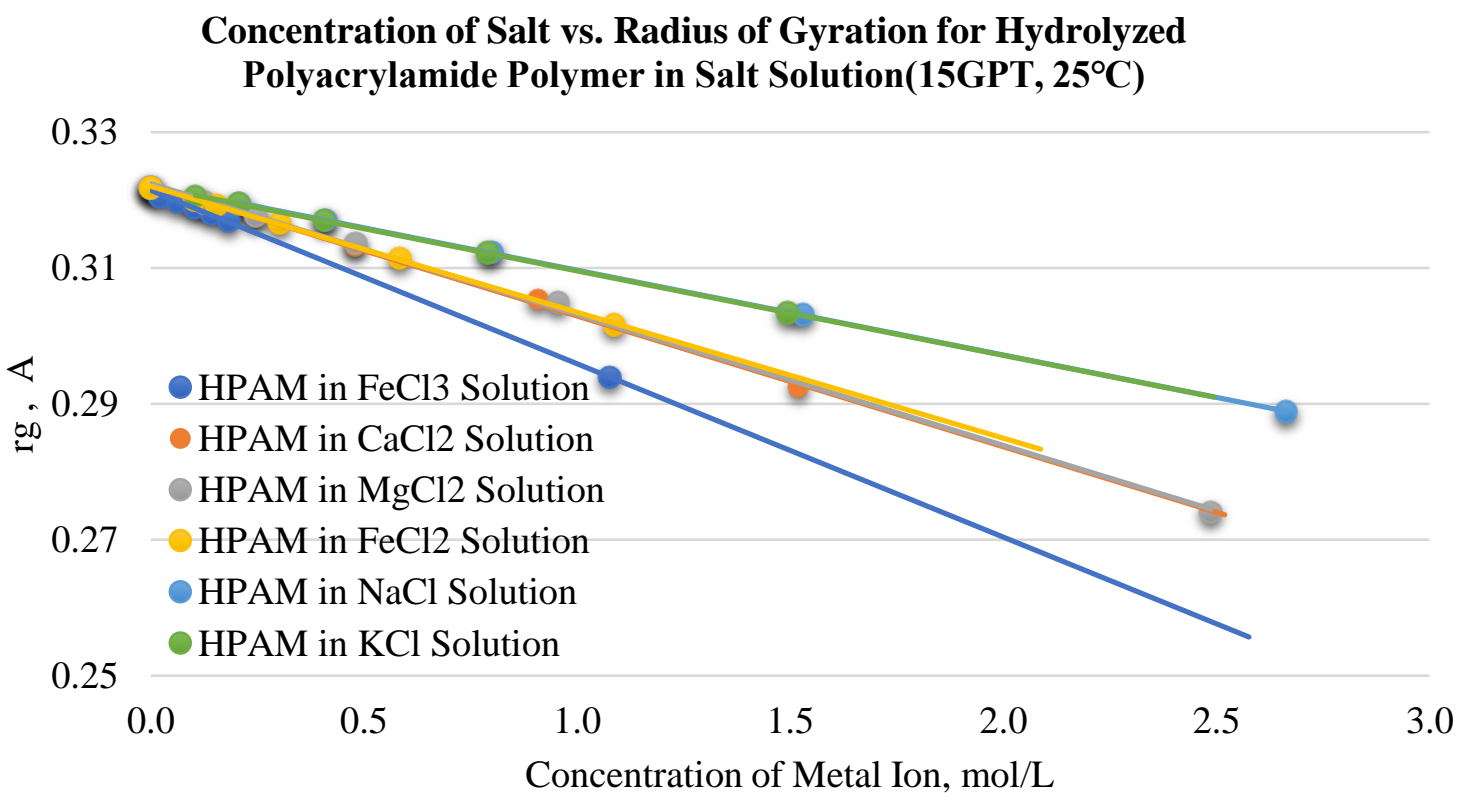

Figure 10-Radius of gyration evolution when HPAM interacts with different metal ions in different concentration.

MD simulations of HPAM also follow a trend that trivalent ions affect polymers more than bivalent ones, and the monovalent affect the polymers the least. 
Verifying the Short-time Simulations with Long-time Simulations. To accelerate simulations, one molecule of PAM polymer with 20 repeating units was used instead of hundreds of thousands of repeating units PAM in each cell. After comparing 20ps with 200ps simulation time, the radius of gyration results matched. It means 20ps simulation time is enough for all PAM and HPAM simulations (Figures 11 through 13).

\section{Concentration of Fe3+ vs. Radius of Gyration for Polycrylamide Polymer in Polyacrylamide Solution (1.5wt\%)}

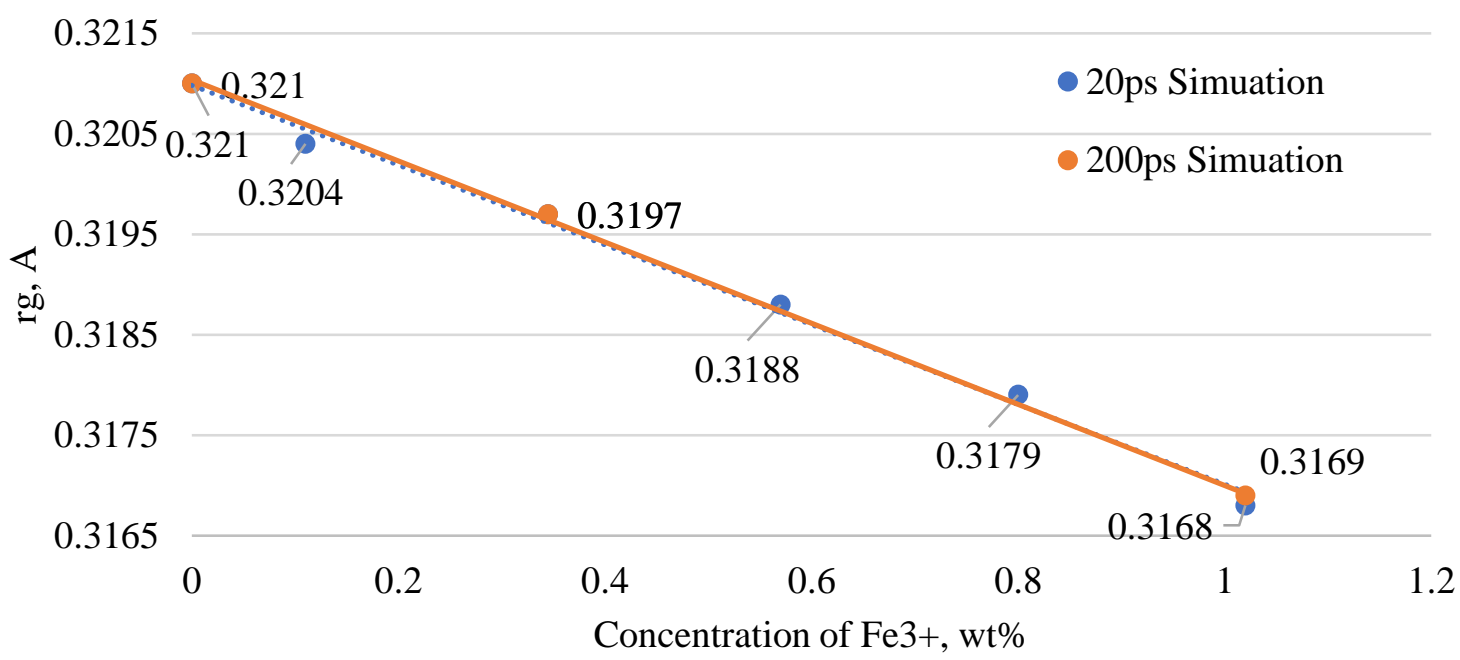

Figure 11-20ps MD simulations vs. 200ps MD simulations in ferric chloride solutions $\left(1 \mathrm{ps}=10^{-12} \mathrm{~s}\right)$.

Concentration of Ca2+ vs. Radius of Gyration for Polycrylamide Polymer in Polyacrylamide Solution (1.5wt\%)

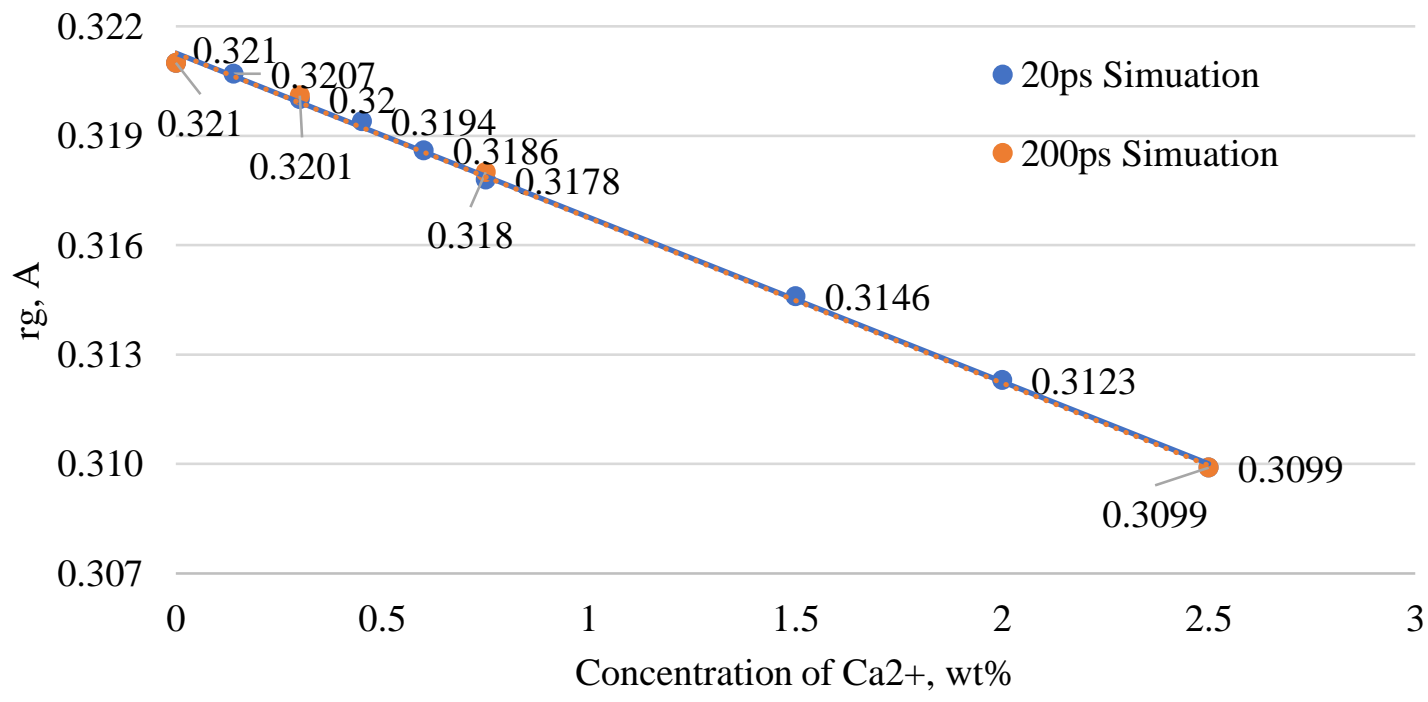

Figure 12-20 ps MD simulations vs. 200ps MD simulations in calcium chloride solutions. 


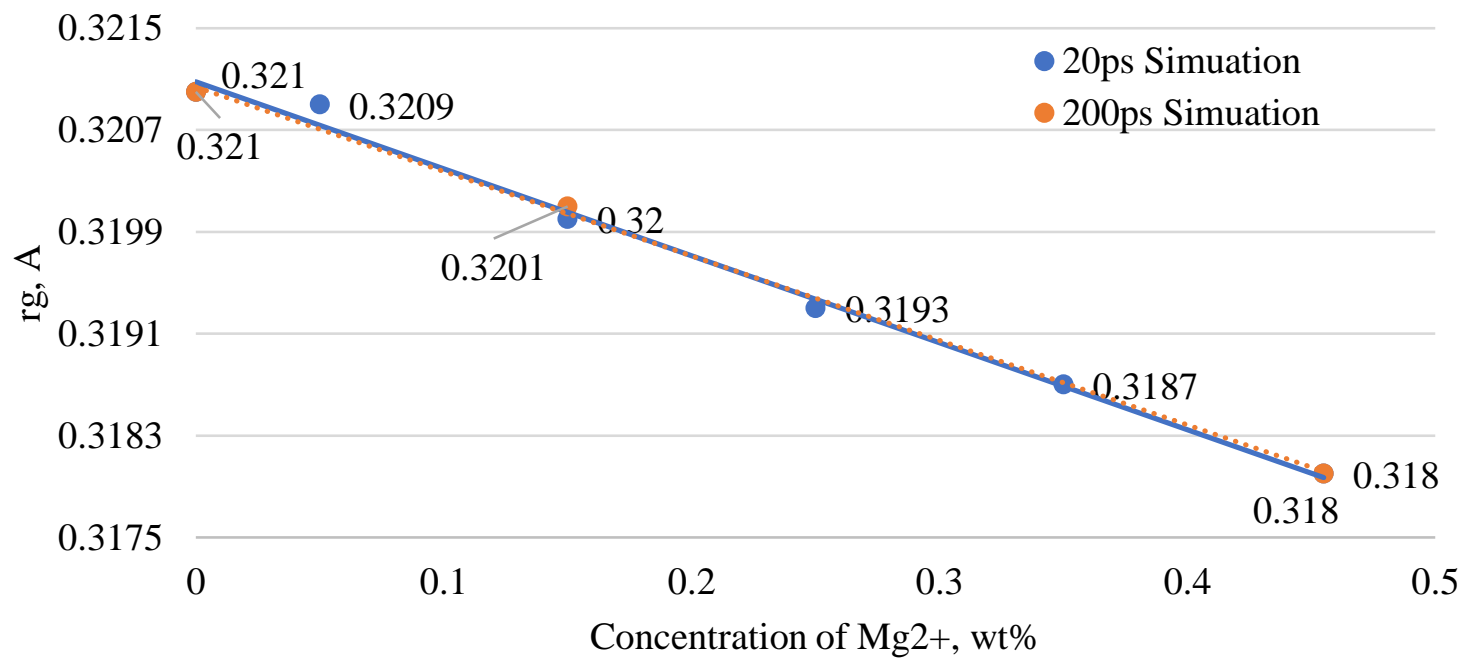

Figure 13-20ps MD simulations vs. 200ps MD simulations in magnesium chloride solutions.

Summary of Simulations Results. The molecular dynamics simulations for typical PAM and HPAM FRs illustrated intra-molecular aggregation so that the $\mathrm{R}_{\mathrm{g}}$ decreases. PAM-based FRs coil in salt water. Intramolecular interactions are obvious with formation damage risk. Long chain and being charged are the two main inherent defects.

Prediction of a New FR for Slickwater without Formation Damage. The simulations results show that PAM-based FRs coil in salt water. Formation damage tends to happen after hydraulic fracturing with slickwater. In the molecular dynamics simulations, it shows that long chain and being charged are the two main inherent defects when using PAM-based FRs.

A new FRs can be predicted, at least including the following features.

1. Relatively shorter polymer chain. The shorter, the better, even a chain as short as one micron. Even if the short-chain polymer coils in salt water, its size is small enough to pass the fractures without plugging or blocking the pores.

2. Without the long chain, the friction-reduction rate could be low. Thus, nanoparticles may be introduced to the low velocity flow zone next to tubing walls.

With these two features as guidelines, one new FR mixture is found.

\section{Effects of Metal lons on HPAM FRs in Water}

Few papers have shown transmittance results that FRs affected by metal ions in water. Metal ions force PAM-based FRs coil, so FRs will lose friction-reduction rate. The transmittance tests show how the pure HPAM FRs are affected by each salt solution. $\mathrm{Fe}^{3+}, \mathrm{Ca}^{2+}, \mathrm{Mg}^{2+}$ and $\mathrm{Na}^{+}$are the representative metal ions that HPAM FRs can encounter during the whole procedure in a slickwater fracturing job.

Experiments. The formula for calculating transmittance is transmittance equals light exiting the sample divided by light striking the sample. In the experiment, wavelength was $600 \mathrm{~nm}$. The HPAM concentration was $0.12 \mathrm{v} \%$, based on field treatment experience. The molecular weight of HPAM was around 12 million. Normalized transmittance data was used to eliminate the time effect of friction-solution change. The HPAM solution samples without salt were set to 100 and all the transmittance test results were compared, allowing for a determination of which kind of salt affects the polymers more than others (Tables 4 and $\mathbf{5}$ ). 
Table 4-Transmittance results of HPAM FR solution with different salts.

\begin{tabular}{|c|c|c|c|c|c|}
\hline \multirow{2}{*}{ Salt } & ppm & Concentration,w\% & Molarity & Transmittance, $\%$ & Normalized Transmittance \\
\hline \multirow{3}{*}{$\mathrm{FeCl}_{3}$} & 0 & 0 & 0.00 & 7 & 100.00 \\
\cline { 2 - 6 } & 10000 & 1 & 0.06 & 1 & 14.29 \\
\cline { 2 - 6 } & 42300 & 4.23 & 0.26 & 1.9 & 27.14 \\
\hline \multirow{3}{*}{$\mathrm{CaCl}_{2}$} & 0 & 0 & 0.00 & 5.2 & 100.00 \\
\cline { 2 - 6 } & 24200 & 2.42 & 0.22 & 6 & 115.38 \\
\cline { 2 - 6 } & 155900 & 15.59 & 1.40 & 11.3 & 217.31 \\
\hline \multirow{3}{*}{$\mathrm{MgCl}_{2}$} & 0 & 0 & 0.00 & 7.9 & 100.00 \\
\cline { 2 - 6 } & 51100 & 5.11 & 0.54 & 13.2 & 116.18 \\
\hline \multirow{3}{*}{$\mathrm{NaCl}$} & 209000 & 20.9 & 2.20 & 7.3 & 100.00 \\
\cline { 2 - 6 } & 0 & 0 & 0.00 & 11.3 & 154.79 \\
\cline { 2 - 6 } & 198800 & 19.88 & 3.40 & 17.3 & 236.99 \\
\hline
\end{tabular}

Table 5-Transmittance results of the less-damaging FR solution with different salts.

\begin{tabular}{|c|c|c|c|c|c|}
\hline \multirow{2}{*}{ Salt } & ppm & Concentration, w\% & Molarity & Transmittance, $\%$ & Normalized Transmittance \\
\hline \multirow{3}{*}{$\mathrm{FeCl}_{3}$} & 0 & 0 & 0.00 & 101 & 100.00 \\
\cline { 2 - 6 } & 6100 & 0.61 & 0.04 & 104 & 103.48 \\
\cline { 2 - 6 } & 29500 & 2.95 & 0.18 & 98 & 97.51 \\
\hline \multirow{3}{*}{$\mathrm{CaCl}_{2}$} & 0 & 0 & 0.00 & 101 & 100.00 \\
\cline { 2 - 6 } & 29800 & 2.98 & 0.27 & 98 & 97.51 \\
\cline { 2 - 6 } & 67600 & 6.76 & 0.61 & 93.6 & 100.00 \\
\hline \multirow{3}{*}{$\mathrm{MgCl}_{2}$} & 0 & 0 & 0.00 & 97.2 & 102.78 \\
\cline { 2 - 6 } & 35900 & 3.59 & 0.38 & 99.9 & 99.59 \\
\hline \multirow{3}{*}{$\mathrm{NaCl}$} & 57200 & 5.72 & 0.60 & 96.8 & 100.00 \\
\cline { 2 - 6 } & 41100 & 0 & 0.00 & 99 & 101.01 \\
\cline { 2 - 6 } & 81500 & 8.11 & 0.70 & 100 & 100.00 \\
\hline
\end{tabular}

The transmittance results indicate that with the same concentration, HPAM solutions have a lower transmittance value. Compared with water, the transmittance of HPAM solution with different salts is less than $20 \%$, while the less-damaging FR solutions are almost the same, clear as Distilled (DI) water. Except for $\mathrm{FeCl}_{3}$, the transmittance value becomes smaller as the metal ion concentration increases. Metal ions force polymers to bend or coil. Without salts, the HPAM polymers mostly relax in water. Most light hits the polymers, and certain wavelength lights are absorbed. So, transmittance is low. As the HPAM polymers are forced to bend or coil as metal ion concentrations increase, more and more space becomes available for light to escape. Therefore, the transmittance becomes smaller and the solutions are clearer (Figure 14). 


\section{Concentration of Salt vs. Transmittance for New FR and HPAM in Salt Solution $(0.12 \mathrm{v} \%, 25 \mathrm{oC})$}

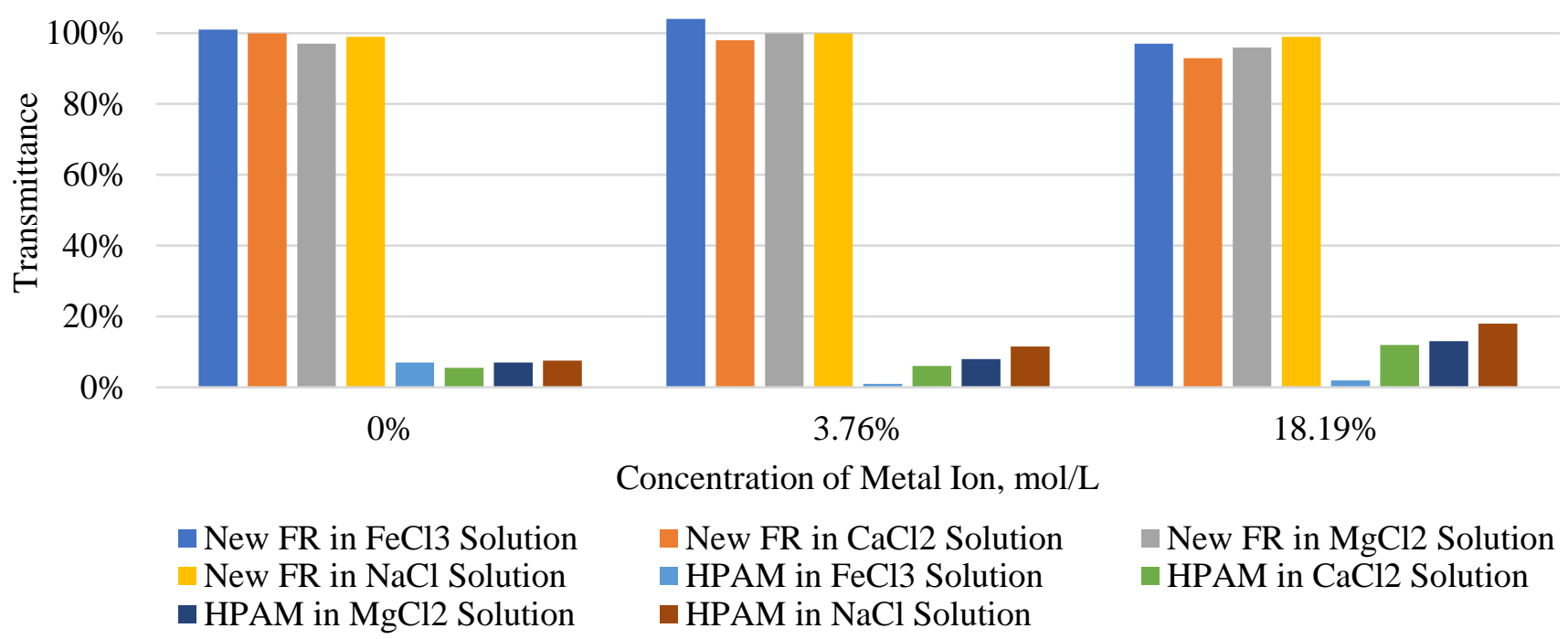

Figure 14-Transmittance results of the less-damaging FR vs. HPAM.

For the less-damaging FR solutions, almost without any large polymers, very few light beams can hit the polymers and be absorbed while penetrating the solutions. In ferric chloride solutions, HPAM reacted with ferric ions and flocculation formed, as shown in Figure 15. There is no flocculation for the lessdamaging FR.

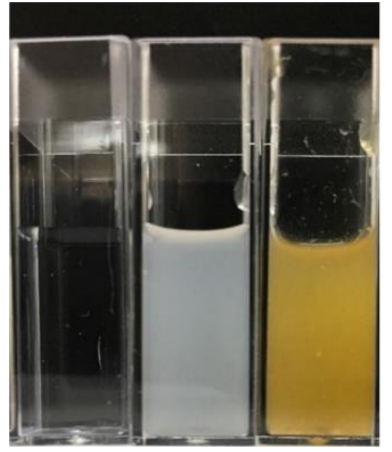

\begin{tabular}{|l|l|l|l|}
\hline & 1 & 2 & 3 \\
\hline DI Water & $\sqrt{ }$ & $\sqrt{ }$ & $\sqrt{ }$ \\
\hline $\mathrm{HPAM}$ & & $1.2 \mathrm{gpt}$ & $1.2 \mathrm{gpt}$ \\
\hline $\mathrm{FeCl}_{3}$ & & & $1.00 \mathrm{w} \%$ \\
\hline
\end{tabular}

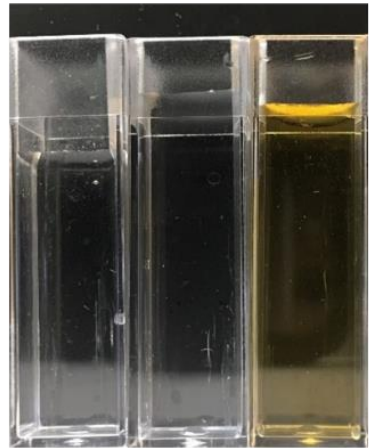

\begin{tabular}{|l|l|l|l|}
\hline & 1 & 2 & 3 \\
\hline DI Water & $\sqrt{ }$ & $\sqrt{ }$ & $\sqrt{ }$ \\
\hline Less-damaging FR & & $1.2 \mathrm{gpt}$ & $1.2 \mathrm{gpt}$ \\
\hline $\mathrm{FeCl}_{3}$ & & & $0.61 \mathrm{w} \%$ \\
\hline
\end{tabular}

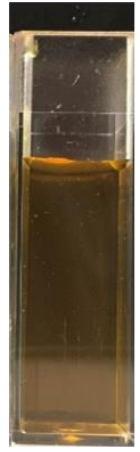

\begin{tabular}{|l|}
\hline 4 \\
\hline$\sqrt{ }$ \\
\hline $1.2 \mathrm{gpt}$ \\
\hline $2.95 \mathrm{w} \%$ \\
\hline
\end{tabular}

Figure 15-HPAM vs. a less-damaging $\mathrm{FR}$ in $\mathrm{FeCl}_{3}$ Solutions (HPAM: reacted with ferric ions and flocculated; Less-damaging FR: no flocculation).

In HPAM solutions with calcium chloride (Figure 16) and the ones with magnesium chloride (Figure 17), as the salt concentration increases, some little white dots can be observed. It could be the very early stage of flocculation.

For all the salt solutions in tests, the less-damaging FR does not precipitate or flocculate. Except for $\mathrm{FeCl}_{3}$ solution, the less-damaging FR's solutions remained as clear as DI water, as shown in Figures 15 through 17. Although, sodium chloride is one of the monovalent salts that affect polymers the least compared with divalent salts and trivalent salts. However, the colors of the solutions with different concentrations are different in Figures 15 through 17. The background is black by design for better clarification of the flocculation process. The higher the concentration of $\mathrm{NaCl}$ is, the clearer the solution, i.e., the black background appears unobstructed. It means HPAM polymers stretch like barriers without 
$\mathrm{NaCl}$, and the more $\mathrm{Na}+$, the more the polymers bend, so more space is available for light to pass through. The dark background (black) intensifies as sodium ion concentrations increase, as shown as Figure 18 (right), which indicates a clearer solution with fewer flocculates.

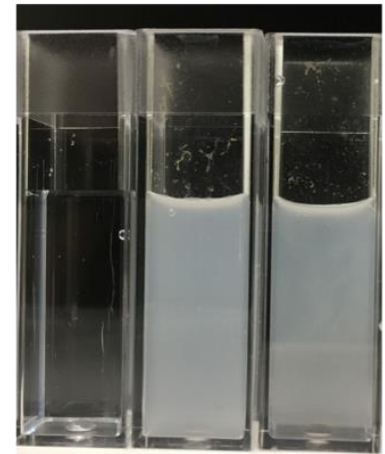

\begin{tabular}{|l|l|l|l|}
\hline & 1 & 2 & 3 \\
\hline DI Water & $\sqrt{ }$ & $\sqrt{ }$ & $\sqrt{ }$ \\
\hline HPAM & & $1.2 \mathrm{gpt}$ & $1.2 \mathrm{gpt}$ \\
\hline $\mathrm{CaCl}_{2}$ & & & $2.42 \mathrm{w} \%$ \\
\hline
\end{tabular}
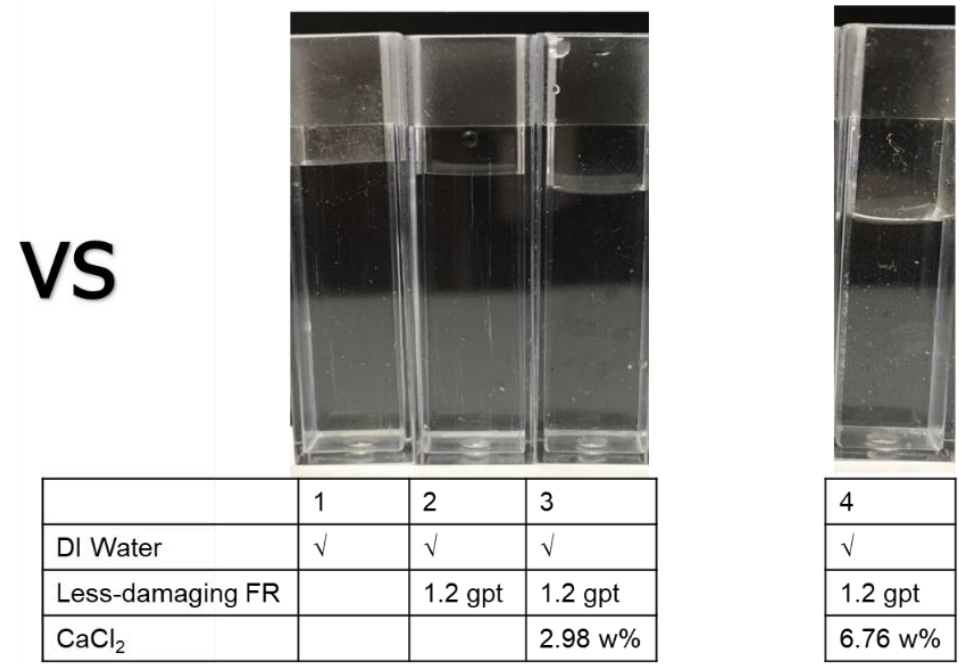

Figure 16- $\mathrm{HPAM}$ vs. a less-damaging $\mathrm{FR}$ in $\mathrm{CaCl}_{2}$ solutions.
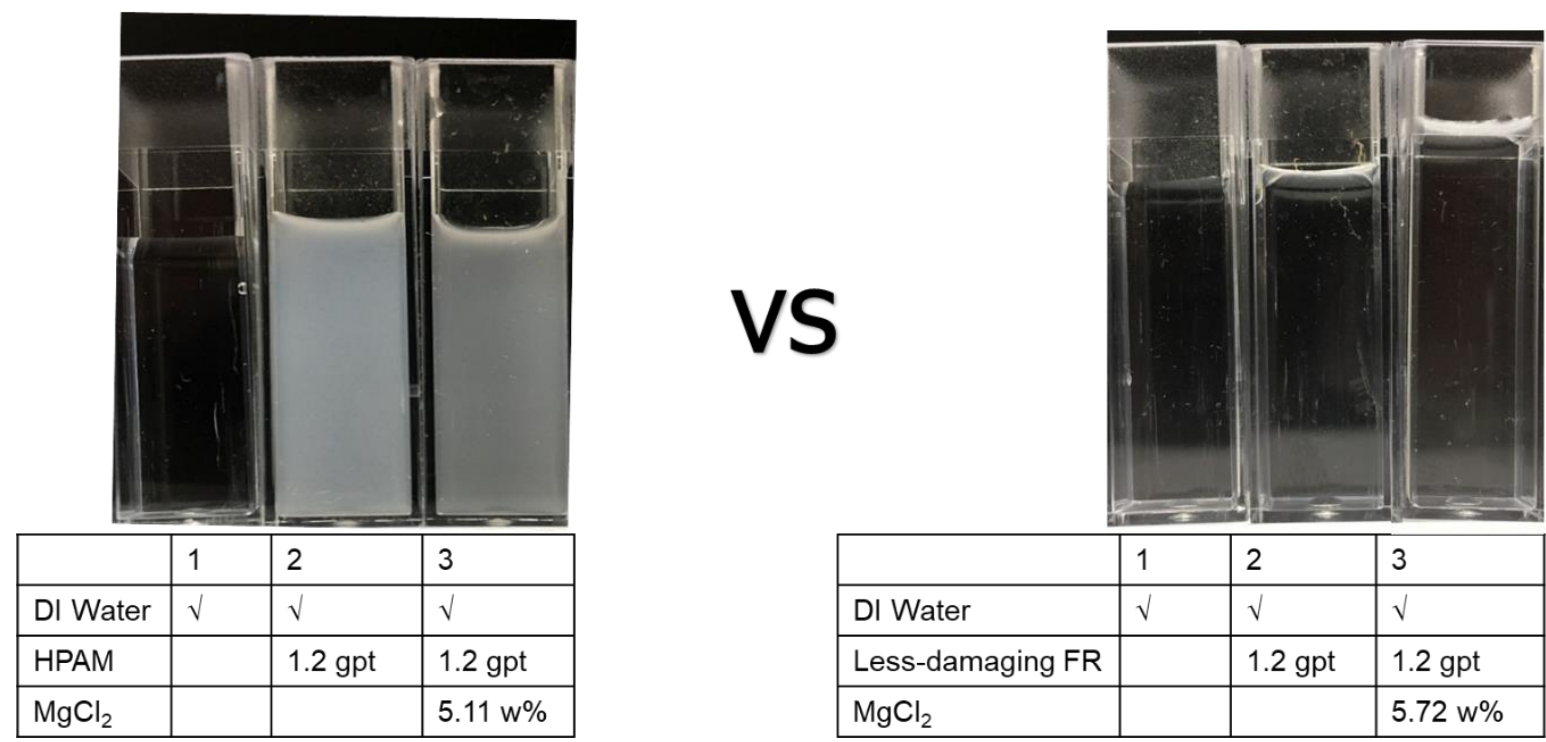

Figure 17—HPAM vs. a less-damaging $\mathrm{FR}$ in $\mathrm{MgCl}_{2}$ solutions. 


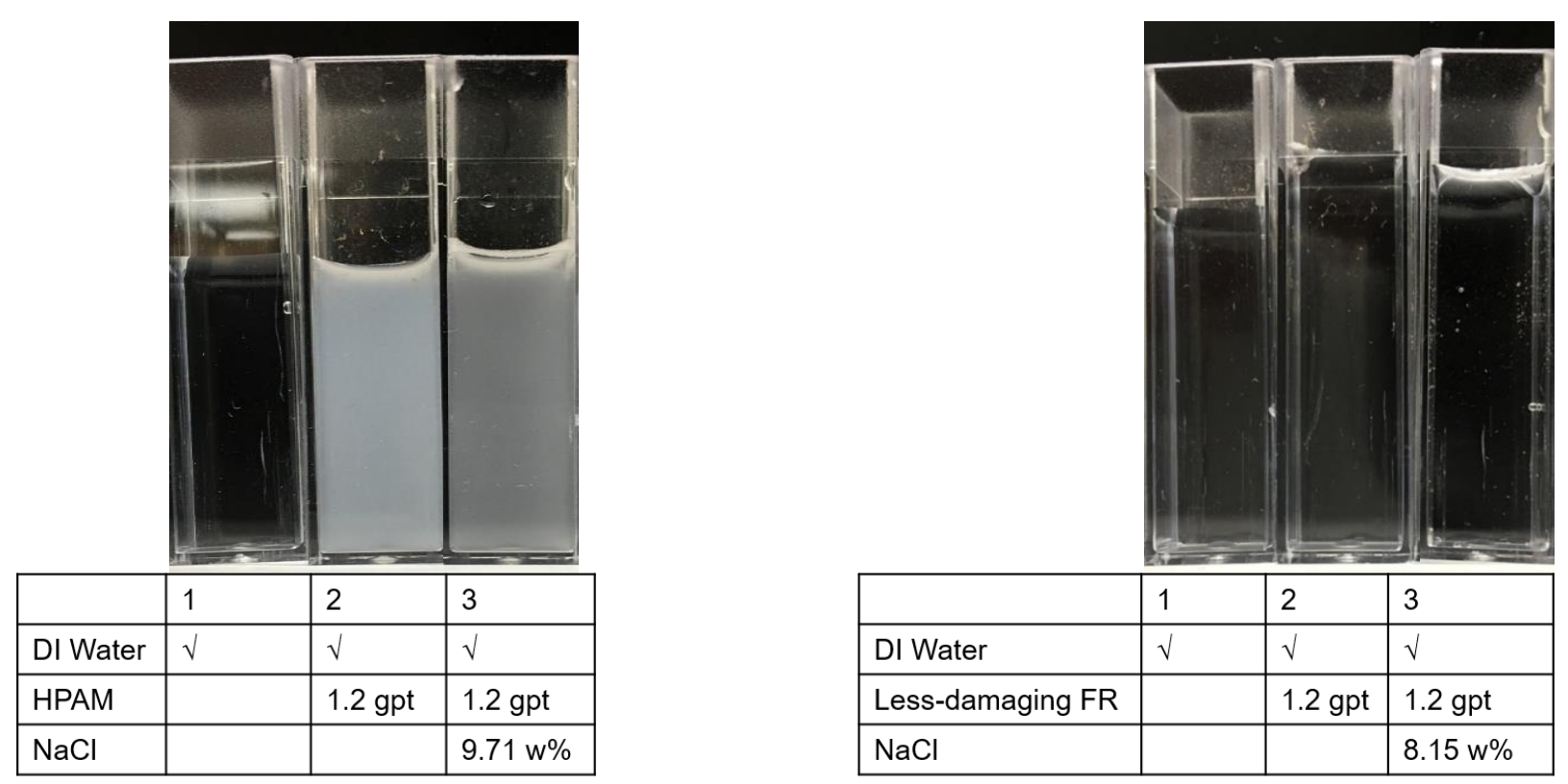

Figure 18-HPAM vs. a less-damaging FR in NaCl solutions.

Viscosity Concerns. For fracturing operations, proppant screenout in treatments is risky for wellbore integrity and equipment safe. Conventionally, viscosity is one of the most important variables for proppant suspension in fracturing fluid (Feng et al. 2017). Stokes' law was applied to designing most types of fracturing fluids, including guar-based fluids, cellulose-based fluids, and PAM-based fluids, in which the sedimentation velocity is inversely proportional to the medium viscosity. Later, the fluid elasticity was found to be another important variable that dominates proppant suspension (Harris and Harold 2000, Naval and Shah 2001; Hu et al. 2015).

In slickwater fracturing in shale reservoirs, the mechanism of proppant transport is different. Since slickwater has only a small concentration of polymers (up to $2 \mathrm{gpt}$ ), it does not have high enough viscosity or elasticity required to keep the proppant in suspension. In this case, the proppant settles faster under static conditions, and proppant transport may be dominated by the movement of the proppant bank itself.

Three proppant transport mechanisms in slickwater have been proposed (Coker and Mack 2013; Sun 2015). At very low velocity, little or no proppant is moved. At higher velocity, proppant grains roll or slide along the surface of the settled proppant bank (reptation creep). At even higher velocity, proppant grains bounce off the surface back into the flow stream (saltation). Dufek and Bergantz (2007) demonstrated that saltation depends on the coefficient of restitution which is defined as the ratio of the velocity with which the object leaves after a collision to the velocity with which it enters the collision. Proppants with a higher coefficient of restitution and a lower friction coefficient than other proppants will be transported deeper into the fracture.

Coreflood Experiment. The goal of fracking is to maximize production, the extent of which is directly linked to how much the formation is damaged after fracking. Table 6 is a set of coreflood data corroborating the less-damaging nature of less-damaging FR (without using any breaker), which shows greater than $99 \%$ regained permeability. 
Table 6-Cores data for coreflood.

\begin{tabular}{|c|c|}
\hline Items & Value \\
\hline Material & Synthetic quartz \\
\hline Dimensions & $2.5 \mathrm{~cm} \times 8 \mathrm{~cm}$ \\
\hline Porosity & $20 \%$ \\
\hline Permeability & $40-200 \mathrm{mD}$ \\
\hline $\mathrm{N}_{2}$ flow time & $>1$ hour \\
\hline Variables to measure & the flow rate and the pressure of $\mathrm{N}_{2}$ gas \\
\hline
\end{tabular}

In contrast, industrial regulars FR-A and FR-B lead to less than 10\% regained permeability, under presumably identical conditions. FR-A is a commercial dry powder FR, and FR-B is a regular emulsion FR. $\mathrm{K}_{1}(\mathrm{md})$ is the initial permeability, and $\mathrm{K}_{2}$ is the regained permeability (Wu et al. 2017). Arising from this less-damaging nature, the use of the less-damaging FR showed astonishing production enhancement of 56 folds or more than conventional means (Table 7).

Table 7-Coreflood results comparison between less-damaging FR to common commercial FRs without breakers.

\begin{tabular}{|l|c|c|c|}
\hline \multicolumn{1}{|c|}{ FRs } & $\mathbf{K}_{\mathbf{1}}(\mathbf{m d})$ & $\mathbf{K}_{\mathbf{2}}(\mathbf{m d})$ & Regained Permeability \\
\hline FR-A & 172.7 & 12.76 & $7.4 \%$ \\
\hline FR-B & 166.3 & 0.5 & $0.3 \%$ \\
\hline Less-damaging FR & 147.7 & 146.5 & $99.2 \%$ \\
\hline
\end{tabular}

\section{Field Tests}

Comparative daily gas production through two wells on the same platform: one well fractured by slickwater with less-damaging FR (Gas Well \#1); the other by a conventional inverse emulsion FR (Gas Well \#2) (Figure 19).

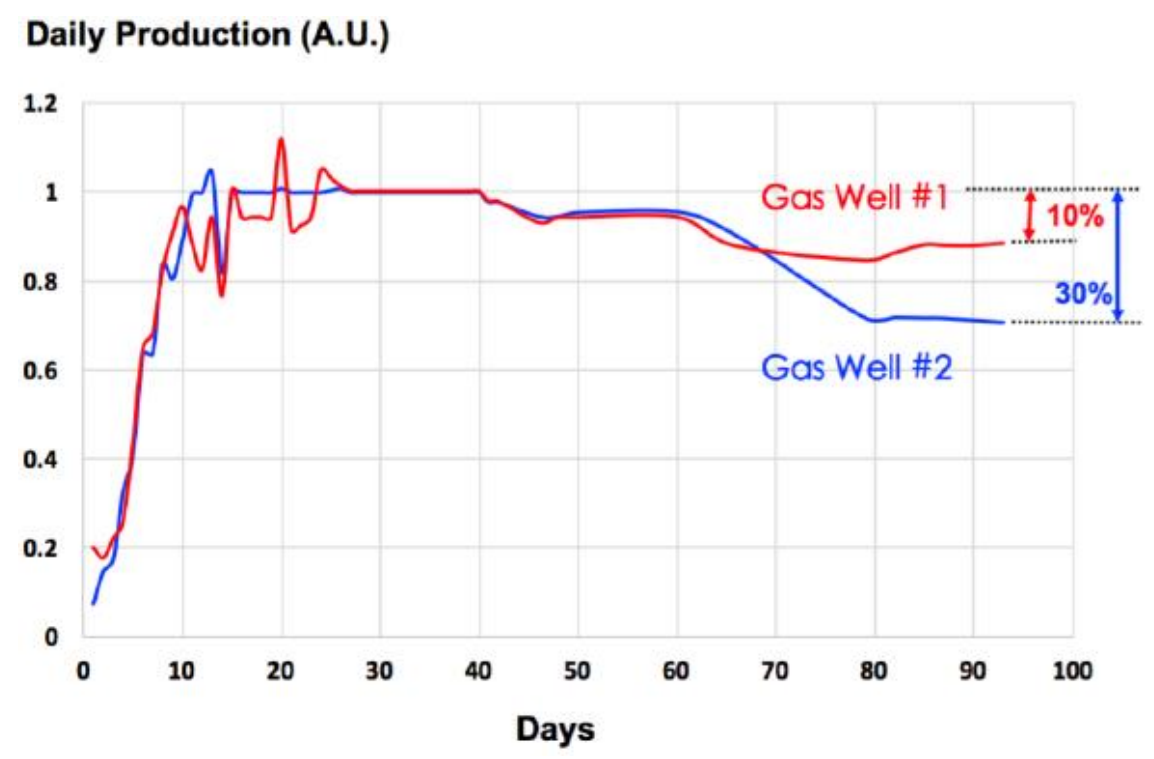

Figure 19-Gas production rate: Less-damaging FR (red) vs. conventional FR (blue). 
Results show that the less-damaging FR is three times more effective at increasing daily gas production than conventional inverse emulsion FR.

- Gas well \#1: decline rate was $10 \%$ after three months of production.

- Gas well \#2: decline rate was 30\% after three months of production.

Gas well \#2 production regime follows the statistical data. The literature reports an average 30\% decline after three months of gas production on 838 wells (Figure 20). However, the well fractured by slickwater with the less-damaging FR saved $20 \%$ of gas production, just by not damaging the formations.

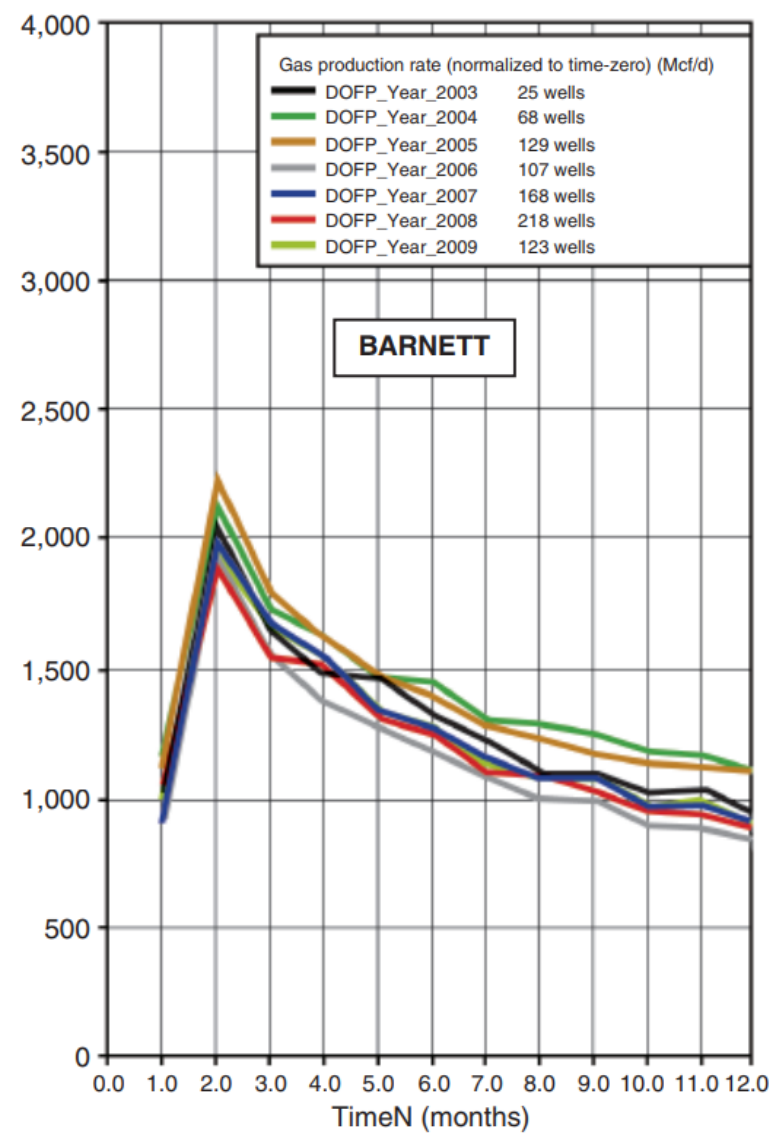

Figure 20-Barnett shale first-year production rates.

\section{Conclusions}

Results of the experimental studies and field tests conducted during this research lead to the following conclusions:

1. A systematic method is found to mitigate formation damage caused by FRs.

2. The MD simulations systemically explain how the commonly used FRs interact with different metal ions in water. Potential formation damage caused by FRs in slickwater is confirmed by both MD simulations and lab tests (UV-vis tests and coreflood tests).

3. MD simulation saved time and cost for new formula inventions.

4. The coreflood and field results substantiate the finding/guidance for a less-damaging FR as impressive and directional.

5. The finding that the shrinkage/aggregation of PAM is most sensitive to $\mathrm{Fe}^{3+}$, then $\mathrm{Ca}^{2+} / \mathrm{Mg}^{2+}$, then $\mathrm{Na}^{+} / \mathrm{K}^{+}$is consistent with the typical FR performance. Most FRs lose performance in the presence of $\mathrm{Fe}^{3+}$. One frequently reduces ferric (by iron reducer) to ferrous to minimize the negative influence of ferric, which is also consistent with our MD simulations.

6. By combining molecular dynamics simulation, prediction, lab tests, and field tests, one more effective FR is found for slickwater with high salt-tolerant, almost non-damage to formations and more gas production. 


\section{Acknowledgment}

Gia Alexander is acknowledged for editorial assistance in preparing this paper.

\section{Conflicts of Interest}

The author(s) declare that they have no conflicting interests.

\section{References}

Barati, R. and Liang, J. 2014. A Review of Fracturing Fluid Systems Used for Hydraulic Fracturing of Oil and Gas Wells. Journal of Applied Polymer Science 131(16):1-9.

Carman, P.S. and Cawiezel, K.E. 2007. Successful Breaker Optimization for Polyacrylamide Friction Reducers Used in Slickwater Fracturing. Paper presented at the SPE Hydraulic Fracturing Technology Conference, College Station, Texas, USA, 29-31 January. SPE-106162-MS.

Coker, C. E. and Mack, M. G. 2013. Proppant Selection for Shale Reservoirs: Optimizing Conductivity, Proppant Transport and Cost. Paper presented at the SPE Unconventional Resources Conference Canada, Calgary, Alberta, Canada, 5-7 November. SPE-167221-MS.

Dill, W. and Smolarchuk, P. 1988. Iron Control in Fracturing and Acidizing Operations. J Can Pet Technol 27(3). PETSOC-88-03-08.

Dufek, J. and Bergantz, G. W. 2007. Suspended Load and Bed-Load Transport of Particle-Laden Gravity Currents: The Role of Particle-Bed Interaction. Theoretical and Computational Fluid Dynamics 21(2): 119-145.

Essington, M. E. 2005. Soil and Water Chemistry: An Integrative Approach. Abingdon, UK: CRC Press.

Feng, Y., Li, X., and Gray, K. E. 2017. Development of a 3D Numerical Model for Quantifying Fluid-Driven Interface Debonding of an Injector Well. International Journal of Greenhouse Gas Control 62(2): 76-90.

Harris, P.C. and Harold, W. 2000. Real-Time Control of Low-Polymer Fracturing Fluids. Paper presented at the SPE Annual Technical Conference and Exhibition, Dallas, Texas, 1-4 October. SPE-63238-MS.

Holloway, M. D. and Rudd, O. 2015. Fracking: The Operations and Environmental Consequences of Hydraulic Fracturing. Chromatographia 78(7):601-602.

Hu, Y. T., Chung, H., and Maxey, J. E. 2015. What is More Important for Proppant Transport, Viscosity or Elasticity? Paper presented at the SPE Hydraulic Fracturing Technology Conference, The Woodlands, Texas, USA, 3-5 February. SPE-173339-MS.

Ibrahim, A. F., Nasr-El-Din, H. A., Rabie, A., et al. 2018. A New Friction-Reducing Agent for Slickwater-Fracturing Treatments. SPE Prod \& Oper 33(3): 583 - 595. SPE-180245-PA.

Jackson, R. B., Osborn, S., Vengosh, A., et al. 2011. Reply to Davies: Hydraulic Fracturing Remains a Possible Mechanism for Observed Methane Contamination of Drinking Water. Proceedings of the National Academy of Sciences 108(43):1-15.

Kaşgöz, H., Özgümüš, S., and Orbay, M. 2003. Modified Polyacrylamide Hydrogels and Their Application in Removal of Heavy Metal Ions. Polymer 44(6): 1785-1793.

Kuila, U. and Prasad, M. 2011. Understanding Pore-Structure and Permeability in Shales. Paper presented at the SPE Annual Technical Conference and Exhibition, Denver, Colorado, USA, 30 October-2 November. SPE-146869MS.

Montgomery, C. 2013. Fracturing Fluid Components. In Effective and Sustainable Hydraulic Fracturing, ed. Bunger, A. P., McLennan, J., and Jeffrey, R., Chap. 2,30-60. London, UK: IntechOpen.

Naval, G. and Shah, S. 2001. A Rheological Criterion for Fracturing Fluids to Transport Proppant during a Stimulation Treatment. Paper presented at the SPE Annual Technical Conference and Exhibition, New Orleans, Louisiana, 30 September-3 October. SPE-71663-MS.

Peña-Icart, M., Tagle, M. E. V., Alonso-Hernández, C., et al. 2011. Comparative Study of Digestion Methods EPA 3050B (HNO3-H2O2-HCl) and ISO 11466.3 (Aqua Regia) for CU, Ni and Pb Contamination Assessment in Marine Sediments. Marine environmental research 72(2): 60-66.

Seright, R.S., Campbell, A., and Mozley, P. 2009. Stability of Partially Hydrolyzed Polyacrylamides at Elevated Temperatures in the Absence of Divalent Cations. Paper presented at SPE International Symposium on Oilfield Chemistry, The Woodlands. Texas, 20-22 April. SPE-121460-MS.

Sisk, C., Diaz, E., Walls, J., et al. 2010. 3D Visualization and Classification of Pore Structure and Pore Filling in Gas Shales. Paper presented at the SPE Annual Technical Conference and Exhibition, Florence, Italy, 19-22 September. SPE-134582-MS.

Sun, H., Zhou, J., Brannon, H., et al. 2015. Case Study of Soft Particle Fluid to Improve Proppant Transport and Placement. Paper presented at the SPE Annual Technical Conference and Exhibition, Houston, Texas, USA, 2830 September. SPE-174801-MS. 
Tessier, A., Campbell, P. G. C., and Bisson, M. 1979. Sequential Extraction Procedure for the Speciation of Particulate Trace Metals. Analytical Chemistry 51(7): 844-851.

Woodroof, R. A. and Anderson, R. W. 1977. Synthetic Polymer Friction Reducers Can Cause Formation Damage. Paper presented at the SPE Annual Fall Technical Conference and Exhibition, Denver, Colorado, 9-12 October. SPE-6812-MS.

Wu, J.J., Yu, W., Ding, F., et al. 2017. A Breaker-Free, Non-Damaging Friction Reducer for All-Brine Field Conditions. Journal of Nanoscience and Nanotechnology 17(9): 6919-6925.

Yegin, C., Jia, B., Zhang, M., et al. 2017. Next-Generation Supramolecular Assemblies as Displacement Fluids in EOR. Paper presented at the SPE Europec featured at $79^{\text {th }}$ EAGE Conference and Exhibition, Paris, France, $12-$ 15 June. SPE-185789-MS.

Rixing Zhang is in the Ph.D. program of petroleum engineering at Texas A\&M University. His research is mainly on the failure mechanism of common friction reducers used in slick-water. He has more than 14 years of experience in completion engineering, especially in high-pressure high-temperature (HPHT) ultra-deep wells.

Hisham Nasr-El-Din is a professor in Petroleum Engineering Department at Texas A\&M University. His research interests include well stimulation, formation damage, enhanced oil recovery, conformance control, interfacial properties, adsorption, rheology, cementing, drilling fluids, two-phase flow, and non-damaging fluid technologies. Nasr-El-Din has nearly twenty patents and has published and presented more than 575 technical papers. He has received numerous awards within Saudi Aramco for significant contributions in stimulation and treatment-fluid technologies and stimulation design, and for his work in training and mentoring. He serves on the Society of Petroleum Engineers (SPE) steering committees on stimulation and oilfield chemistry, is a review chairperson for the Society of Petroleum Engineers Journal (SPE J.), and is a technical editor for SPE Production \& Operations (SPEPO) and SPE Development \& Completion (SPEDC).

Xiaochun Jin has integrated industry, academic, management, and investment experience across Asia, America, and the Middle East. He has been dedicated to commercializing clean technology in the fossil industry, and industrializing clean energy. His investment portfolio includes biotechnology, geothermal energy, smart microgrid, hydrocarbon exploration \& production, etc. He worked at BP America, Weatherford, and Blade Energy Partners, Energy \& Geoscience Institute at the University of Utah. He has published 20+ papers in peer-reviewed journals and SPE conferences. Dr. Jin holds a Ph.D. degree in Petroleum Engineering from the University of Oklahoma.

Jun Jim Wu is the President \& CTO of Phoenix C\&W, Inc. He received his Ph.D. from the University of Toronto in 2004 and held various technical and managerial positions in multinational companies. His accomplishment is manifested by over 20 peer-reviewed journal publications in prestigious journals such as Journal of the American Chemical Society and Macromolecules, as well as 20 granted patents.

Lisa M. Pérez is the Manager of the Laboratory for Molecular Simulation at Texas A\&M University. She strives to reveal the benefits of molecular modeling and computational chemistry to researchers and students at Texas A\&M University and to curious minds of all ages through outreach events. She has more than 10 years of research experience in the theoretical investigation of reaction mechanisms for transition metal containing enzyme systems. 